This item was submitted to Loughborough's Research Repository by the author.

Items in Figshare are protected by copyright, with all rights reserved, unless otherwise indicated.

\title{
Technology transfer and the British furniture making industry 1945-1955
}

\section{PLEASE CITE THE PUBLISHED VERSION}

http://dx.doi.org/10.1353/ctt.2004.0006

\section{PUBLISHER}

Johns Hopkins University Press @ The Colorado Institute for Technology Transfer and Implementation

\section{VERSION}

AM (Accepted Manuscript)

\section{LICENCE}

CC BY-NC-ND 4.0

\section{REPOSITORY RECORD}

Edwards, Clive. 2019. “Technology Transfer and the British Furniture Making Industry 1945-1955”. figshare. https://hdl.handle.net/2134/9471. 
This item was submitted to Loughborough's Institutional Repository (https://dspace.lboro.ac.uk/) by the author and is made available under the following Creative Commons Licence conditions.

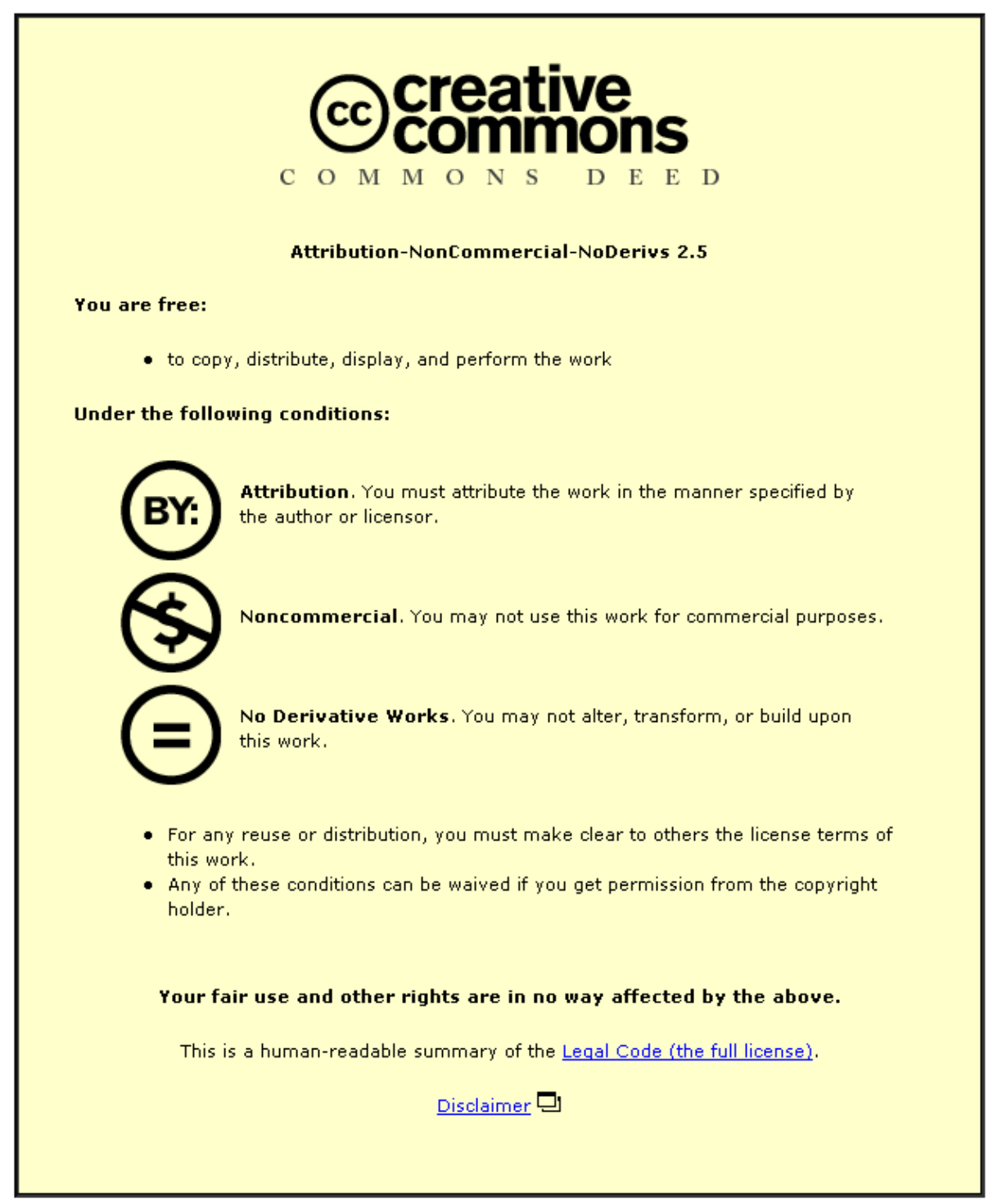

For the full text of this licence, please go to: http://creativecommons.org/licenses/by-nc-nd/2.5/ 


\section{Technology transfer and the British furniture making industry, 1945-1955}

\section{Introduction}

The transfer of technology from both allies and enemies in a wide range of manufacturing industries has been a notable feature of the aftermath of both world wars during the twentieth century. This paper investigates whether this pattern is as evident in the furniture trade as in other, more strategically critical products. The two world wars were significant factors in the development of the British furniture industry, particularly because of the transfers of materials and production technology that took place after each. While events of the 1920s and 1930s indicated the possibilities of significant advantages from such developments, much the more important era followed World War II. The paper will track these changes in the period 1920-1955, but with the main emphasis falling on the decade after 1945. The results suggest that the manufacturing models from the U.S. were significant, but that the possibilities were unevenly adopted throughout the industry. Moreover, the government played a significant role in facilitating some of the most significant transfers. The paper finally assesses the impact that transfers to and within the furniture industry may have had in the longer term. The selected time period of the main case study relates to both the post-war adoption of new techniques and materials and to a particular moment when the British government specifically encouraged productivity as a goal.

Technology transfer is often seen as a phenomenon occurring between nations, but I am also using it to define the transfers within an industry where wartime emergencies sometimes became enabling factors. Much of my methodology has been derived from the work of David Jeremy (1992) and Everett Rogers (1983 and 1995). In particular I follow Jeremy with the common questions that technology transfer raises (Jeremy, 1992, p.3) but have applied them to my particular study. I also take heed of the cautions pointed out by Jeremy in his example of the transfer of Fordist mass production to the UK, where the transfer was effective technically, but was hindered by particular social and political aspects of the receiving parties. Rogers, in his work on diffusion of innovations has provided a similar framework that has informed my work. The idea that an innovation may be an idea, a practice or an object is relevant to my case study as is the notion that diffusion occurs through time and that it is often an important variable in the process. In particular the aspects of diffusion that relate to social systems and the boundaries of the members and their mutual goals, is considered in relation to my case studies.

The adoption of new technologies requires a network of promoters and distributors who encourage the process, often in the face of hindrances from other agencies. Implementation depends upon economic attitudes and financial resources, technical perceptions of appropriateness, as well as an ability to accept, adapt, and then apply new technologies. In addition, cultural factors such as education, training, personal attitudes and political factors including trade unions, state controls and governmental intervention, all have an effect. Diffusion relies on breaking down barriers, developing change agents, and promoting and creating an infrastructure A case study of the British furniture industry from 1920-1955, a period of considerable turmoil, offers an opportunity to see how firms in that industry responded to the opportunities that emerged in the aftermath of the two wars. There was no formal structured transfer process at work, but particular businesses transferred systems as appropriate to their local conditions. The 
ultimate impact of changes prompted largely by wars and their aftermath on the British industry was substantial.

\section{World War One and furniture production technology}

During the first half of the twentieth century, the British furniture industry in particular was often slow in embracing modern techniques. Wartime necessity, however, provided a powerful impetus for change; thereby hinting at the way wartime experiences could encourage the diffusion of new ideas and processes into furniture making firms. The diverse and varied nature of the industry militated against a homogenous approach to change. Mainly organised within numerous small factories that often utilized limited equipment, the industry frequently relied on craft-based operations combining hand and machine tools as appropriate, in conjunction with particular mechanised aspects of materials handling and factory layouts. Although there were some larger-scale exceptions, the majority of the industry operated on variations of this model. It is of course perfectly reasonable to operate in this manner, since the nature of the British market was (and still is in some cases) completely suited to a small-scale, flexible batchproduction system.

Despite the apparent lack of interest in modernising the industry generally, the First World War and its aftermath provided an opportunity for sectors of the furniture trade to raise themselves and their standards to those that characterized modern manufacturers. The underlying development in the case of technological change was the transfer of methods from other industries, allies, and enemies, to furniture making. The changes were especially important in relation to the experience of working to precision tolerances, working with new and composite materials, and the application of new production systems and technologies to furniture design and making. This meant that the firms which (a) applied the benefits of the transfer of technology from industries unconnected with furniture, (b) applied technically advanced materials developed during wartime conditions, and (c) were willing and able to improve their management of the factory, obtained an edge over the competition in peacetime.

The war work undertaken during 1914-18 gave a particular impetus for change. For many furniture makers, the requirements of military contracts often encouraged the introduction of simplified processes of working and scientific management schemes that until then were alien to small furniture makers. These techniques included the batch production of interchangeable parts (American system) and the introduction of largescale production of single items, and, later on, high-precision wood engineering methods that allowed manufacturers to adapt to changing furniture design schemes. The sorts of work ranged from the production of tent pegs, through specialised invalid furniture to aircraft propellers.

For the companies involved, the changes from craft working to engineering blueprints required were more than a cultural shift: it was an entirely new way of working, with its own new vocabulary and new tools. ) The importance of these changes was not lost on contemporary commentators. In 1917, the trade press wrote, 'during the past twelve months there have been in the furniture trade several developments of historic interest. The most important of these is the definite entrance of the industry on the work of aircraft construction' (Cabinet Maker, 29.12.1917). The furniture manufacturer, Hermann Lebus later wrote: 'Whilst our personnel were accustomed to interpreting 
drawings and prints of relatively simple articles, aircraft blueprints which showed assemblies, sub assemblies, and everything in the greatest detail, including all the metalwork, represented a new language'. (Lebus, 1947: 34) and in October 1918, another commentator noted that 'the experience gained in the process of standardization is bound to have its effect on the factory operations of the future'. (Cabinet Maker, 26. 09.1918)

By 1920, The Times newspaper could neatly sum up the results of 1914-18 war work for the furniture industry:

Having regard to the world shortage of furniture, perhaps the most valuable result of wartime experience will be the education of our manufacturers in mass production. The absolute accuracy and precision demanded by the A.I.D. [Aircraft Inspection Dept.] for all aeroplane work accustomed heads of factories to the idea that intensive production need not necessarily mean bad work. (28.02.1920)

Although the references to the apparently widespread adoption of standardization and mass production techniques might be disputed, the transfer of aeroplane production technology proved influential in some firms. The Times further commented on the management of these businesses:

The pre-war factories, with their wartime experience are better organised than before and are being run on scientific lines. This of course applies especially to the production of everyday furniture of the kind that is and for some years will be required in immense quantities. (28.03.1920)

The Lebus company undertook such moves immediately after World War I, when management decided to make large quantities of cheaper furniture. In 1920, the company minutes record this comment: 'it appears that the new class of furniture must be made on American methods, and that the firm has resolved to apply such methods to all its furniture'. (Lebus, 38.) To meet this challenge, the directors of the firm visited the United States to learn how the technologies employed there could be adapted to the needs of the firm. The visit proved successful as they placed orders for American machinery; developed plans to produce limited product ranges; adopted new finishing processes based on US models and laid out the factory on American lines. This example of the transfer and adoption of new technology based on an individual company initiative was not indicative of other parts of the trade at this time.

It is also worth noting that members representing workers on the Standing Committee on the Investigation into Prices of Furniture had some reservations about the changes in production methods that had occurred:

The difficulty of obtaining sufficient skilled labour is due to the sectionalising process introduced in many factories by employers, which makes it increasingly difficult to develop craftsmen and constitute a somewhat alarming menace to the prestige and stability of British production (Profiteering Acts 1919 and 1920, p. 4).

The fears of the erosion of craft skills in the face of new technology demonstrated here 
remained an inhibiting factor in many later attempts at technology transfer. However, the technical and operational changes brought about by the changed circumstances following the war undoubtedly accelerated the development of technology in certain parts of the industry. Although these developments were only a prelude to the much more intensive attempts at transfer after the Second World War, they at least pushed consideration of technology and production transfers onto some manufacturers’ agendas.

\section{Experience from World War II}

By the end of the 1930s, despite a number of experiments, most firms in the British furniture industry continued to operate largely as they had before 1914. But the impact of the second war was much greater and more extensive. The war left few firms untouched and prompted changes not only in production techniques, but also in materials use. In 1939, there were approximately 2,000 factories in Britain making wooden furniture, bedding and fabric-based objects. By 1943, only 200 remained unengaged in some form of war work.

Until the 1940s, furniture makers almost naturally used wood. The1939-45 wartime demand for a wide range of wood-based products, ranging from tent pegs to aircraft, gliders, and landing craft meant that furniture producers could fully participate in the war effort. As in World War I, it would again be the work on aeroplanes, and this time that experience opened the door for significant technology transfers when peace returned. Through their efforts in aircraft construction, some of the larger manufacturers gained valuable experience, not only in factory organization, but also in the use of a wave of new materials and processes.

To give an idea of the range of work undertaken, the 1945 press release from furniture manufacturers, F. Wrighton and Co. of Walthamstow, London explained:

During the period the thousand work-people at the factories have manufactured well over one million wood and metal components sub-assemblies and main assemblies for aircraft of all types including Mosquito fuselages, Mosquito wings, Hamilcar cockpits complete with controls, Proctor centre sections, Oxford empennages, Albemarle main planes, Stirling coupes, Spitfire and Seafire Elevators, Horsa glider ailerons, Mosquito jettison tanks, as well as being entrusted with the prototype manufacture of aircraft still on the secret list.(Cabinet Maker, 16.06.1945)

One of the most successful projects was the production of the Mosquito aeroplane, which became, in the mythology of the furniture trade 'the furniture-makers' plane'. Initially, in 1942-3, up to 400 woodworking firms began work on the aeroplane; a plane that had been especially designed for speedy manufacture utilising skilled wood-workers. Indeed, the design called for hardly any metal at all. By using jigs, the whole fuselage was engineered from a stressed skin plywood and balsawood sandwich, (fitted with hardwood reinforcing-ribs), which acted as strong, but relatively lightweight material, ideal for the purpose. At the time, furniture producers considered this solution a very good material since it overcame the lack of stiffness inherent in traditional plywood. It was also in this work that the new technology of low-voltage glue heating and gap-filling glues were first used. It is important to remember that the factories engaged in this work mainly produced 
components or part assemblies that aircraft makers later completed. . Other technology was also developed in the furniture factory including aspects of electrical wiring, the use of Perspex canopies, formed plywood drop tanks for Mosquito planes, laminated wood propeller blades, plywood naval motor launches, and so on.

The sub-contracting of the production of the Mosquito aircraft was successful as it transferred pre-planned technology and systems based on uniform designs and close tolerances. Between 1942 and 1945 up to 700 sub-contractors successfully produced 5,500 Mosquito planes. This transferred knowledge and the experience afforded to those manufacturers was used later in Britain to produce the government-sponsored Utility range of furniture, as well as later peacetime product ranges. Government commentators thought that this experience might be the basis for increasing productivity in the post-war industry (Working Party Report.1946: British War Production, 1945).

The transfer and adoption of wartime plywood technology was one of the key factors in the post-war development of the industry. Although there were some notable exceptions, most manufacturers had previously used simple sheet plywood for the backs and bottoms of carcase furniture. Sophisticated moulding and shaping techniques developed for wartime use eventually were transferred to furniture making. An example was the moulding of plywood by a patented process whereby veneer strips were cut to fit a mould shape, then covered with resin and cured in an autoclave, using the rubber bag vacuum method. (Logie, 1947) Used initially for drop fuel tanks on Mosquitoes, the industry later adopted the process for chair seats and then transferred the basic idea to fibreglass furniture technology. The furniture company, Morris of Glasgow, undertook the direct transfer of technology from wartime work on laminated wood propellers to domestic furniture, leading to the manufacture of a range of modern furniture that employed the decorative properties of laminated woods.

It was not just wood materials that were part of this changing picture. The role of aluminium is an important aspect of this story of transfer. In Britain, promotion of aluminium was considerable in the immediate post-war period. During the summer of 1945, an exhibition entitled 'Aluminium-from War to Peace' was displayed in the Exhibition Hall of Selfridges, the London department store, and nearby an aluminium house was erected, complete with a range of aluminium home furnishings. The transfer of technology here was an economic opportunity: economic in the sense of recycling and using stocks not required, in place of scarce woods. In June 1946, the industry requested an investigation into the future of aluminium as a furniture material. The research branch of the British light alloy industry, Aluminium Laboratories, published an internal paper that explored the existing and potential market for aluminium furniture. (Aluminium Laboratories Ltd.: 1946). In this report, the reasons for the use of aluminium were given as either its particular suitability, or as a substitute for orthodox materials. Kitchen units and equipment fell into the first category and bedroom furniture into the second. The report considered that bedsteads, dressing tables, wardrobes, wall units, drying cupboards, and 'cupboard cum bookshelf ' were the most likely furniture items to be developed, as the light weight of the metal was an advantage, 'provided it was not accompanied by flimsiness and metallic operation'. (Ibid) However, there was no attempt to develop radically new designs and the examples the report showed were based on copies of existing models of wooden Utility examples, metal office furniture, or pre-war designs of a nondescript nature. Interestingly, the Utility furniture scheme did include aluminium divan bed-frames, and plans were made for a range of coloured aluminium- 
framed dining chairs c. 1946-7. (Geffrye Museum: 1974).

One particular application of technology transfer is found in Heal's Plymet furniture of May 1947. The direct references in the trade catalogue to the transfer of technology from aeroplane manufacture to its use in furniture, are representative of the interest in the new possibilities arising from the war. The furniture was described as being made from

A new technique for bonding metal to wood [that was] developed during the war and employed in the construction of aircraft. The aluminium sheet is veneered on both sides to make a metal-cored plywood. The sheet is then curved to form the outer skin of the furniture and bonded to the structural frame of the steel. In this way, the best qualities of wood are combined with those of metal. The outer veneer displays the pleasing figure of fine wood and gives warmth to the touch so lacking in other metal furniture, whilst the aluminium core and the metal framework contribute strength and rigidity. No rivets or bolts, which so often mar the appearance of metal furniture and give it an ugly engineering character. ( Heal Plymet catalogue: 1947)

The result appears to be a clever conjunction of the new technology with the traditional requirements of the customers. This hiding of the new technologies, literally under a veneer of tradition, would become commonplace.

In addition to cabinetwork, metal frames for chairs were developed from the war technologies. In 1942, Dr. West, of The Wrought Light Alloys Development Association drew attention to another example of potential transfer:

The very comfortable chair which is used in aircraft, for example, by bomber pilots. It is built up on a light alloy tubular framework, covered with sponge rubber and then with fabric. I would commend that type of furniture to the serious attention of furniture designers, putting forward its light weight as one of its major advantages. (Braddell:1942, 312-3).

There were serious moves to encourage the use of surplus aluminium from aircraft manufacture by the furniture industry, and the British aluminium trade press was enthusiastic about 'news of the proposed setting up in this country of an aluminium furniture industry on a large scale' (Light Metals, October 1946:. 557). However, Gordon Russell, who was charged with investigating the feasibility of the idea, suggested it would only work if there were a complete timber shortage. (G. Russell, 1968: 213). The inhibiting factor here was again the character of the 'traditional' craftsman-maker who had a powerful position at the time.

One of the most famous British chairs of the twentieth century was undoubtedly the aluminium BA chair. Designed and manufactured by Ernest Race, its success can be seen in the fact that between 1945 and 1969 c. 250,000 chairs were produced. In this case, the use of aluminium was again seen as a pragmatic substitute for wood, and its was not considered by Race to be the beginning of a new furniture-making technology. What was important about this chair was the new relationship between precision metal engineering and furniture manufacture, which produced furniture at a reasonable cost and in a design that was forward looking in design (White, 1973:15). 
In the United States, the aluminium industry had grown by 600 per cent during wartime and by 1945, it was clear that industry promotion of aluminium was necessary to use the increased capacity that, in a post-war situation, was, in fact over-capacity. Writing in 1960, R. B. Wemyss of Reynolds Metal's design department indicated the issues facing the post-war manufacturer. He saw that

[our] talents...are directed towards advocating new uses and applications for aluminium in current markets and proposing new projects and design concepts for potential markets of the future. The purpose of our design efforts is to stimulate the thinking in other designers in industry towards a practical use of aluminium in their own particular design projects. (Industrial Design, May 1960, 59.)

In other words, aluminium technology had to be transferred to industries that were not yet familiar with it. The manufacturing infrastructure was complete so it was said that: 'the aluminium industry is in a good position to encourage inventiveness in design: it feels secure in its ability to shape almost any reasonable product concept'. (Ibid) In fact, in the immediate post-war period, the aircraft industry, which had been a major user of aluminium, did begin to diversify production. For example, the Cessna aircraft company turned to contract furniture as one way of expanding its customer base, and albeit making furniture in a tried and tested style, it produced storage units with drawers lined in aluminium. (Interiors, 1949, p. 108.) By 1950, it was said of Cessna furniture that this furniture market had 'proved so successful that the company sampled the commercial market by sales-testing a new line at the Marshall Fields store in Chicago. Its success seems evident as it was reported in the trade press that aluminium furniture was to be 'mass produced by assembly line techniques on a 31/2 mile conveyor in the company's Hutchinson, Kansas plant'. (Modern Metals, June 1950. 21.) The trade journal concluded its review of aluminium furniture by saying 'with proper design, quality workmanship, and intelligent promotion, aluminium fabricators might well establish a firm foothold in the profitable furniture business'. (Ibid) The three major manufacturers of aluminium indeed made massive efforts and promoted the material very effectively. Ten years later, Henry Dreyfuss commented on the producer's success: 'They have spread the word about the design possibilities of their material, and have succeeded in establishing a connotation of modernity which older industries have reason to envy'. (Dreyfuss, Industrial Design, 7 May 1960:56.)

The cultural inhibitions of the trade and its customers could be subverted by adapting the materials to recognised styles without losing the technical advantages transferred from other applications. This effect was demonstrated in 1949, when furniture makers, Parker Knoll, used aluminium alloy in the frames of the Toledo fireside wing chair. ( Bland, 1995:115.) This model (PK707) which was based on a traditional armchair format had its frame made by aluminium die-casting specialists High Duty Alloys, (who had undertaken much aeroplane work) but was sprung and upholstered in the Parker Knoll factory in a relatively standard way (Regd. Design No. 853391.) The frame was painted a wood colour and fitted with kapok-filled cushions and arm pads so that any modern connotations were hidden. The transfer of aluminium technology was successful as it was seen as appropriate to parts of the furniture business at that time. The use of plastics during the war also had an impact on post-war manufacturers and designers. The case of the Eames' fibreglass side chair demonstrates the transfer well. 
Initially the US Air Force developed polyester plastic, reinforced with fibreglass, during the war. Eames saw the potential of this material for furniture and began to develop his ideas. The wartime manufacturing experience with fibreglass materials of the Zenith Plastics (now Century Plastics) of Gardena, California, was combined with the design skills of the Eames's and the furniture manufacturing company Herman Miller, to make a highly successful range of fibreglass reinforced chairs. Like the plywood examples above, the key in this case was the transfer of wartime experience to new designs of furniture. As Pat Kirkham says: 'the Eames's had achieved their ambition of bringing the benefits of a sophisticated military development to 'ordinary people... at non-military prices'. (Kirkham,1995: 236) This is a perfect example of the benefits that could accrue from the transfer of military applications of technology to domestic use. In fact, these examples confirm the features of technology transfer already referred to above, including the profit motive, (in this case of the manufacturer and supplier), the perception of the appropriateness of technology to new applications by the designer, and the developing post-war culture and infrastructure to implement them.

The extent of the industry's involvement in war work necessitated organizational changes, technical adjustment, and, most importantly, new attitudes that often paid dividends in the post-war period. For example, the sub-assembly principle, derived from wartime experience on aircraft manufacture, was particularly singled out as it 'reduced to a minimum the amount of work that had to be done in the main assembly jig, and [it] enabled the higher skills of the available workers to be used to utmost advantage'. (Board of Trade, 1946, p. 86) Looked at in another way, the changes meant that semi-skilled and skilled employees could be engaged more productively in the more demanding aspects of the work whilst machines undertook the repetitive, but demanding parts of the work. In addition to the sub-assembly principle, the facilitation of orderly progress through the factory was also considered an important development. The application of production engineering methods that some of the larger furniture making concerns made, would appear to have given them an advantage over their smaller competitors in the post-war markets, but the output per employee evidence does not support this. (See Table C below) Other improvements that were transferred included the introduction and widespread use of power clamps, autoclaves, synthetic glues, and quick-setting glues. All of these were transferred directly from war work and were capable of being adopted in various ways by a range of furniture making enterprises.

The wartime experience was, therefore, one that brought adjustment to much of the traditional industry. For some it enabled the introduction of important new methods of production engineering and management, and for others it enabled them to return to their traditional practices, but often with new insights that might be partially adopted. For nearly all of them, the war had created the circumstances for thinking about the organization and arrangement of their plant and the manufacture of their products. After the War the focus of attention moved from immediate responses to pressing needs, to a broader model of future change that was often considered in terms of the experience of American industry.

\section{Americanization}

British interest in American methods of production and management has had a long history and in the mid-twentieth century, the American model with its core 
characteristics of standardization, automation, job evaluation, time and motion study, flow line layouts, mechanised mechanical handling, and quality control was often cited as the ideal. Needless to say, these attributes were not adopted across the industry, (or even in a majority of firms), and even those that were, often had modifications and transformations applied selectively. Indeed Jonathan Zeitlin has pointed out that the mass production and systematic management practices of some parts of American industry before World War II were unlikely to 'be a universal model of industrial efficiency', especially in the furniture industry where product diversity and productive flexibility were more and more important in maintaining a competitive edge. (Zeitlin and Herrigel, 2000, p. 125-6) Even more to the point are the comments of Tomlinson and Tiratsoo who consider that:

Far from being a crass attempt to export a simple model of 'mass production' or Fordism to Britain, the US productivity drive in Britain should be seen as an attempt to persuade British firms to become more efficient, but to do so in a manner consistent with their actual and potential market circumstances. (1998)

In terms of furniture manufacture, this comment allows for the fact that issues of standardization and economies of scale have to be considered in relation to the need for specialization and flexibility, thus creating an uneven association, which is reflected, in the varied development of the industry. Indeed the British furniture manufacturers were pragmatic in their adoption or avoidance of potential technology transfers and seemed complacent in their own abilities. An editorial in the furniture trade press commenting on an Anglo-US productivity initiative concluded that the British industry, in terms of productivity 'in effect more than holds its own with Uncle Sam' (Cabinet Maker 19.04.1952). Nevertheless, the British Government at least, was interested in investigating American practice, and by extension, transferring methods and best practice to the United Kingdom.

\section{Productivity and the state's involvement in technology transfer}

Some national governments, interested in promoting design and manufacture, publicly exhibited the direct applications of the transfer and adoption of wartime manufacturing systems and materials to the peacetime economy. These transfers might be from other countries or from other firms or industries. The Canadian National Research Council supplied the 1946 "Design in Industry" Exhibition, with examples of plywood aeroplane parts and details of the use of autoclaves in plywood component manufacture. The exhibit demonstrated the potential of technology transfer. The idea was intended to transfer the technology of aeroplane plywood working to chair making. Two prototype chairs by the Canadian Wooden Aircraft Company and the Granby Aviation Company were displayed. These chairs, made on the same principles as aircraft fuselage construction were shown with didactic panels that explained the benefits of the process. In addition, examples of other wartime materials adapted for post-war use were shown. These included an aluminium cantilever chair and experiments in plastic and glass fibre, again derived from wartime technology (Collins, 1988).

The British government took a similar approach. For example, in the Britain Can Make It exhibition held in 1946, the display entitled 'From War to Peace' exhibited a 
new type of saucepan, developed in part from the manufacturing methods that were initiated by research on the sturdiness of Spitfire aeroplane exhausts. The transfer of aluminium fabrication technology from wartime aircraft demands to the production of commercial furniture is another example of this process. (Edwards, 2001) Interestingly, this was mainly developed by businesses outside the mainstream of furniture making and was relatively short-lived.

Whatever the efforts made, the British furniture industry was undoubtedly in a state of hiatus as it moved into the second half of the century. As part of a wider program of industrial rehabilitation, the British government set about the task of assisting in the reorganization of the furniture trade, amongst other industries. Even during hostilities, the Government had set up a Furniture Industry Post-War Reconstruction Committee who reported on proposals for structural changes.

Transfer processes usually were based on a mix of Government-sponsored investigations (usually with important 'actors' from within the industry), the publications of working groups, the trade press, and initiatives by private firms. The channels of transfer that the Board of Trade established were Working Parties for various industries, charged with examining the plight of particular industries and providing recommendations for future growth and organization. In the case of the Furniture Working Party, the individuals appointed included important furniture manufacturers, furniture trade unionists, and design consultants. These persons were highly influential within their own social networks, and proved crucial to the adoption and implementation of any recommendations.

In the immediate post-war era, the furniture industry was ripe for change. The Furniture Working Party reported on the disparate nature of the industry and its organization:

The picture then is of an industry consisting of a relatively small number of large firms working on mass-production lines and in general organised accordingly; a large number of medium-sized firms with a fair amount of mechanical equipment but in many cases a system of organisation more in keeping with the craft days than with current methods of production; and a large number of small firms making some use of machine techniques, but in general methods and direction still very much the handcraft business (Working Part Report, 1946, p.10).

By extension parts of the industry could have benefited from technology transfers and expansion based on modern business methods. The comparative table below demonstrates why the Government appeared to have a point with regard to furniture manufacturing. Using comparative data from 1939, the Working Party Report showed the following:

\section{Insert Table A here}

In other words, just prior to World War II, the American industry overall achieved 63\% more in terms of net output per worker. The other important factor was that for existing 'modernisers' in British cabinet-making businesses employing more than 500 workers, the difference was small, implying that they were already taking advantage of 
improvements in the manufacturing process. On the other hand the large-scale upholstery companies were less productive, used older technology, and were more likely to resist change. This was partly due to the bespoke nature of their business, and partly because it was not seen as practicable to apply flow line systems to the product.

The brief of the Furniture Working Party reported upon steps that 'should be taken in the national interest to strengthen the industry and render it more stable and more capable of meeting competition in the home and foreign markets'. (1946, p.3) Part of this political agenda was to visit other manufacturers (particularly in the USA) and create a network of access to information and ideas. Here we see technology transfer occurring in the traditional sense. Although there were many similarities, the Report of the Working Party on Furniture highlighted the differences between the American and the British experiences. For example, the sub-group who visited the United States in 1946 were impressed by the degree of mechanization and the productivity levels that they considered were attributable to spacious and well-planned factory floors. The visitors commented positively on the absence of wardrobes in manufacturers' ranges and the loose fitting of drawers, both of which reduced assembly times; the speedier polishing and drying methods, and the internal movement of items within the factory, designed to limit the amount of manhandling. They also commented favourably upon the fact that all the operations seen both in cabinet and upholstery workshops, were sub-divided to be more efficient. (Ibid, Appendix, p. 158-67) This latter fact accounts to some extent for the wide discrepancy in upholstery output in Table A.

The Working Party Report demonstrated that higher output per head (i.e. productivity) in the USA was based on a set of particular factors: spacious well-lit premises; less timber handling due to factories being located close to railways; superior layout of material flow from yard, to kiln, to mill; better equipped machine shops with no 'fitting' easy mechanised flow-through polishing shop and use of drying chambers; efficient transport between floors; a more serious approach to planning; the breaking up of operations in upholstery to increase productivity; a freer exchange of information and the importance placed on production planning. (p. 88) The Working Party Report concluded that a major problem for the British industry was that the 'traditional methods of the handwork shop were grafted on to the new machine production industry'. (p.88) It appears that the rate of adoption of technology transfers is only as fast as the slowest link.

The results of the Working Party convinced the Attlee government to push the furniture industry to adopt US-style production and management methods as ways of maintaining full employment and boosting output. One outcome of the British Industrial Organisation and Development Act (1947) was the establishment of a development council for the furniture industry. The functions assigned to the development council included scientific and technical research to benefit the whole industry; promoting a greater degree of standardization of products; improvements in marketing and distribution; better and more uniform methods of cost accounting, and the collection of statistics (Henderson, 1952, pp. 452-462). All these ideas were based on the findings published in the Working Party Report of the previous year. In 1949, the Furniture Development Council was established, but widespread fears within the industry of Government interference, or worse still, control, left it rather an impotent tool of change. A review of the trade literature of the period reveals a strong rejection of real or apparent Government 'interferences' in the trade's organization, partly based, no doubt, on the highly structured and restrictive experiences of wartime and immediate post-war 
restrictions and controls (Cabinet Maker, 1946-50) Nevertheless, there were more direct attempts at technology transfer.

In 1948, the British government, in collaboration with the United States, had established the Anglo-American Council on Productivity to assist British industries in trying to raise the level of their productivity. A range of manufacturers was involved, including furniture. This is another example of Government-assisted attempts at technology transfer, which operated in conjunction with some commercial firms. An American commentator on a trade delegation, reported that one particular reason behind the Government's encouragement of these visits was that

Material handling of 'work in progress' is backward in most English factories. Conveyorised plants such as we have in America are virtually unknown in Britain. In some of the larger factories, pieces in production are placed on the floor between operations. This not only adds greatly to the cost but also increases the liability of damage to the various parts (BFM, Private Papers, 1949).

This specific criticism was also widened to include disapproval of the state of British factories immediately after World War II. The American trade delegation also found that: Most English factories are of multi-storey construction and, with few exceptions, are very old buildings to which additions have been made. Small windows result in poor lighting and the old uneven floors are very inferior. Housekeeping in most plants is not of the high level we know in this country (Ibid).

In 1951, not long after this disparaging analysis from American colleagues, a British team, under the auspices of the AACP, went to the United States to visit manufacturing businesses with the following terms of reference.

To study methods of production, including administration, layout, plant methods and operating conditions in the American Furniture Industry; to report thereon and to formulate recommendations for the increase of production efficiency in the British Furniture Manufacturing Trade (Anglo-American Council on Productivity, 1952. p. 1).

In the following year, they published a Report on Furniture in which they commented in the preface that

It was not expected that revolutionary changes would be found in America, but the Team hoped to find in application special methods and special devices in construction, machining, and finishing which are not in general use here [U.K.]. This hope was amply justified. (Anglo-American Council on Productivity, 1952, p. $\mathrm{x}$ )

The Report stressed not only the importance of production engineering and materials handling in the United States businesses, but also the minute division of labour they employed which was considered essential for the efficient running of the plant. (p.4) This was in direct contrast to the often craft-based individualist approach of much of the British industry.

One particular aspect, materials handling technology, was high on the agenda. The 1951 Report said that in the USA there was a desire 'to remove from everyday employment the drudgery of constant lifting, carrying and setting down. In these matters 
the British furniture industry has much to discover'. (p. 7) The materials handling question was apparently crucial:

The American worker sees no virtue in work, which produces nothing, and very readily accepts such aids to production and in many cases demands them. This in turn means that American goods are produced at a lower cost in man-hours, and with full employment man-hours are one of Britain’s most valuable assets. (p. 10)

Although the Report acknowledged that financial restraints limited the adoption of new materials handling equipment immediately, they stated that 'many British managements should pay greater attention to the solution of this problem, as in it may lie the chief difference between American productivity and British’ (p. 10)

There is some evidence that the issue of materials handling seems to have been a success in terms of transferring American practice to Britain. The Review of Productivity noted that since the publication of the Productivity Report in 1952, 'Many firms have reorganised their layouts and have installed various types of handling equipment such as roller conveyors, pendulum conveyors, motivated conveyors, and trucks'. (P.16)

The team, having exhaustively considered the American industry, made recommendations in their report. (p. 70-1) Interestingly, they addressed their particular conclusions specifically to either management, the man in the factory, the industry, trade organizations or Government authorities. However, the spirit of the conclusions was based on an aphorism quoted by the leader of an American team visiting the British cotton industry. He pointed out that 'if you have a dollar and I have a dollar and we exchange dollars, we both have one dollar: but if I have an idea and you have an idea and we exchange ideas, then we both have two ideas' (p. 70). This surely sums up one aspect of technology transfer very neatly.

\section{Adoption Networks}

It might be thought that the traditional clash of science and craft would be a serious problem for furniture-makers, especially upon resumption of peacetime activities. However, the benefits of flexible approaches to production, new factory layouts, motion study techniques, quality control, and planned labour relations were largely acknowledged in principle by the trade, although the various sectors of the industry interpreted these terms differently for their own ends. There was no appetite for a 'one size fits all' approach. Jonathan Zeitlin reminds us of the connections between wartime aircraft manufacture, that like much furniture making, was based on quantity or batch, rather than mass production. (Zeitlin, 1995) Furniture-makers did not generally offer long runs of the same objects produced year in year out. As in the wartime aircraft industry, they responded to changes by incremental improvements and design modifications as demands altered and new ranges had to be introduced.

One attempt to bridge the gap was a standardization scheme intended to limit the diversity of designs offered by British manufacturers. The Government initiated this in Britain during World War II as an expedient. Firms were restricted by the Government Utility scheme to producing $25 \%$ of their pre-war range of designs. According to the Working Party Report, many manufacturers soon realised the economic sense of the reduced product lines and tried to keep to the lower level after the war in order to improve efficiency. However, standardization was not particularly applicable after the first phase of the Utility scheme, especially with the freeing up of design. 
Little could be done before the lifting of raw material controls, but as soon as this happened, improvements to the British industry were actively considered. One would have thought that an influential diffusion method was through the trade press. But it was not. The response to the Anglo-American Council on Productivity Report was limited to a single editorial comment (Cabinet Maker 09.01.1954) and a trawl through the contemporary press reveals far greater concerns in other aspects of the industry, particularly relating to Government control over design, production levels and financial controls.

However, in 1953, the Cabinet Maker ran a long series of articles by William Kape, principal of the London Furniture College, which evaluated all the then current processes and methods in the furniture industry. Discussing the need to adopt a scientific approach to furniture making by employing 'mass production' methods, Kape pointed out that the process must be applied to all aspects of manufacture, and single out waste disposal, materials handling, the rapid setting of adhesives by electronic methods, and work study as areas for improvement. He also set great store by time-study as the basis of accurate costing, hence profitability. (Kape, 1953) It was the latter factor that influenced decisions about adopting other technologies.

Although the physical production difficulties caused by the diversity of ranges discouraged ‘mass production’ techniques, manufacturers set about making cost savings wherever possible. For example, to try to overcome the machine re-setting problem, the system used by Lebus in the late 1940s is worth recording. It apparently consisted of a library, with drawings and costs of each item used in the construction, from the smallest item to each sub-assembly. When a new model was introduced, the maximum number of existing bits and pieces would be used. As design changes were usually superficial, this was easy. (Pritchard, 1984)

This process, derived in part from aircraft manufacturing experience, and in part from the example of US factory management planning, compares favourably with the traditional method that was to make full-scale marked out panels to be used as templates, and from these derive completely new cutting lists and quantities to guide the mill operation for each product line.

An assessment of the work that had been undertaken in the previous few years on the subject of productivity and technology transfer appeared in 1954 as A Review of Productivity in the Furniture Industry. The review considered that the Productivity Team report of 1951 was important but its influence had not been great. Although it was discussed at local meetings and at two conventions organised by the British Furniture Manufacturers' Federation, the Report noted it 'was not discussed in the industry to anything like the same extent as many others [industries]. It is a pity that no special conference was held 'to allow as detailed consideration of the Report as was given to, for example, the Footwear and Hosiery Reports’. (British Productivity Council, 1954)

This appears to reflect the laissez-faire nature of the industry as signalled in its own press. Conversely, although this apparent lack of interest may seem to indicate the inherently reactionary nature of the furniture trade, the Review of Productivity in the Furniture Industry noted that many of the ideas published in the 1951 Report were actually being implemented in some parts of the industry. The major issues of costing and methods engineering were the most important. The Review noted that in terms of costing, it was the legal obligation to produce cost data for the Ministry of Supply, which 
introduced modern costing techniques to furniture factories, many for the first time. (p. 14) The Review was also pleased to see that individual companies were comparing costs and learning from the American experience of openness within the trade as a positive way of transferring ideas and setting criteria. (e.g. Table B) These examples of good practice sometimes faced obstacles: 'Co-operation between employers has increased particularly during and since the war. Yet to some extent, the industry retains the characteristics of a craft, including a certain unwillingness for manufacturers to take competitors' into their works'. (p.14) This inflexible attitude had been commented upon in the 1951 Productivity Report, which had said 'A closed door keeps out more than it keeps in'. (p.71) But changes did occur.

In 1954 the Furniture Development Council, taking up one of the ideas transferred from America, established an industry-wide comparative cost scheme. This enabled manufacturers to judge themselves against an industry average and thus assess their productivity and profitability against these benchmarks.

\section{Insert Table B here}

These evident improvements, although only three years shown here were, at least partially, brought about by developments in productivity which themselves were to a degree rooted in transferred technologies and ideas.

Finally, the Review went on to give case studies of transferred practices. In the business of Alston, for example, 'at each assembly point a small gantry has been erected recently with the requisite pneumatic tools attached. This is an idea taken from the automobile industry'. (p.22) In the upholstery branch, the breaking down of the work into operations was such that the production of a suite has been cut from some 13 hours to 6-7 hours. In the cabinet factory, the reorganization of the layout meant that 'in the last three years, Alston has increased its productivity by some fifty percent and its costs have decreased by about twenty-five percent. (p.22)

Another instance resembles a textbook take up of transferred technology. The firm of P. Leach apparently doubled the output of the factory after the visit of a director served on the A-A P C. visit in 1951. 'The main increase has been achieved by adding to the number of air-driven small tools; by utilising unskilled labour to serve qualified journeymen; by alteration of layout; and by standardization of products and simplification of assembly methods'. (p.2)

A third example, that of Coorsh Brothers of Glasgow, was cited as having more than doubled its output in the machine shop, wood mill and upholstery sections by a vast amount of reorganization, including the extension of payment by results systems, simplification assembly, progress control and pre-planning. (P.30)

The following table looks at the nationwide results hinted at by these examples.

\section{Insert Table C here}

The table clearly shows that the two 'winning sectors' of the trade were the smaller enterprises (1-24 employees) which achieved a $46 \%$ increase in output per employee whilst decreasing the total number employed by $23 \%$, and the large enterprises with more than 500 employees who achieved over $100 \%$ increase in output per employee with just a $14 \%$ rise in total employees in the period 1948-54. This would seem to 
indicate that both the small enterprises and the larger-scale businesses benefited from changes, the small ones by adopting new techniques grafted onto craft systems and the larger scale ones by the economies of scale, combined with revised and adapted technologies. When compared to the figures for 1939 (Table A) where the average net output per employer in the UK was only , 274, a significant and extensive improvement is visible.

\section{Inhibiting factors}

Culture clashes and lack of compatibility with other values is often a feature of any attempts at technology transfer. In reference to the post-war situation, a contemporary author, John Sawyer (1954) considered that even if American production methods were transferred successfully, the social and cultural influences might inhibit the successful transfer of technologies and hinder their adoption. Sawyer identified these factors in general terms as differences in American and European attitudes to manufacturing systems, consumption patterns, and attitudes to and by the workforce and the nature of management. In addition, one might add a British aversion to 'anything American', outdated attitudes to research and development and entrenched methods of wage bargaining and payment systems. Although the possibility of employing skilled and semi-skilled workers using general-purpose machinery reflected a flexible approach to manufacturing in a market-oriented business, the cultural attitudes of the receiving industry often hindered the transfer of technology and the application of new materials. The issue of the maintenance of skills levels and the ideals of craftsmanship were genuine concerns, but old-fashioned ideas and pragmatic methods that had successfully worked for a generation or so may also be seen as inhibiting factors in the transfer process. Nevertheless, a significant but gradual result for the British furniture industry at least, was the acceleration of a change in culture from the 'workmanship of risk', where craft skills manipulated intractable materials, to the 'workmanship of certainty' where mechanised materials handling, machine-assisted production, planning, and synthetic materials created a more reliable manufacturing process and subsequent outcome. (Pye, 1968)

Another inhibiting factor was furniture manufacture's identification as a fashion business. The problems associated with that type of work seemed to be clearly different to both the demands of war and the technologies of mass production. The crux of the marketing restraints on the transfer of American technology and practice to European countries was in the comparative size of the markets. As the OEEC Technical Assistance Mission for the Furniture Industry Report of 1953 noted; 'even though the individual [American] manufacturers simplify their output, the furniture stores can still show a wide range of products by buying from different manufacturers all over the country’. (1953)

\section{Later impact}

In the summary of the report of the OEEC Mission, a revealing phrase suggested a particular direction for the European industry:

When the Mission left for America it was composed of two teams, one to study mass production and one to visit small factories. But it was very soon discovered that there is only one system in America that of line production, whatever the size of the factory. (P.117) 
This 'discovery' of line production and its associated practices (especially materials handling) was probably the major technical change that transferred directly from American to European practice. In many cases, the issue of unsuitable premises inhibited the application of line production. The problem was that a large number of factories were old, multi-storeyed buildings that retarded the full development of flow-line production. Even if they were well equipped, there still existed a problem of movement between floors. Not surprisingly, by the second half of the century, there was a greater tendency to build single-storey factories to allow the development of successful flow production.

It is clear then that productivity markedly increased in some parts of the industry due to a number of factors related in part to the forces of technology transfer, whether from wartime experience or from other countries. Firstly was the use of new costefficient materials, and improved production techniques. Secondly there was a new understanding of management methods and systems, especially cost control and workstudy. Thirdly was the growth of capital investment in the industry that included the installation of materials handling equipment, special-purpose machines, and control systems. The fourth factor was the growing adoption of simplified and rationalised designs to reduce the number of processes and components.

In the case of furniture, the wartime experience and the Government's push gave an impetus to a trade that was conservative by nature and custom. . The incentives were to increase profitability and productivity and to cut costs through improved technical or managerial methods. The opportunities offered by developments in other industries or countries were adapted to the cultural conditions in the market concerned, and all these were pushed by a political agenda. The fact that the new processes and technologies were adopted in a piecemeal manner, and that any transfer technology was often periodic and partial, reflected the clash of cultures that occurred when an often craft-based organization gradually developed strategies for dealing with changed technical and economic situations. An additional inhibiting factor was the diverse and uneven nature of the industry.

Although the development of machines and production management in furniture making has taken great strides in the twentieth century, the nature of the British trade has been such that it will support a large number of relatively small enterprises that co-exist with a comparatively small number of larger ones. One of the reasons for this relates to the findings of an industrial geographer who also identified the limitations on a furniture business in the 1960s:

Furniture is an industry in which the economies of scale in a single plant fail to yield higher returns beyond a rather modest size. It has been estimated that the most profitable kind of firm is probably one only in the 50 to 100-worker range even today. (Martin, 1966) (See also Table D below)

Even if large-scale businesses were not particularly suited to making British furniture, increased efficiency usually equated with better profitability, so some technical transfers and cultural innovations to improve productivity and earnings should have been adopted from early in the century. Although it is understandable that mass production techniques were not used, the application and development of American techniques such as assembly conveyors, time study and sub-assembly, factory layout, rate fixing, and quality control should also have become part of this process early on. However, even in America, the concentration of operations in furniture making resulted in the four largest businesses 
having only $13 \%$ of national sales in 1972, and in Britain, the five largest businesses took about $14 \%$ of national sales in1973. (Prais, 1981, p.138) Concentration was not the only answer. Prais suggests one reason for this:

Efficiency has not depended upon some massive scheme for rationalising industry into a few large capital-intensive production units, with a long vertical integrated flow production... Efficiency has depended rather on the introduction of new processes and new machines by a great many manufacturers... applying general technological advances to the special needs of furniture production. (1981, p. 141)

Indeed, these were exactly the aims of the productivity drives and initiatives of the 1940s and 1950s. In 1949, a director of Lebus Ltd. (at one time the biggest furniture factory in the world) could say,

It is my view that mass and flow production supplements, but does not do away with, the older forms of individualistic production which continues, and must always continue, to play its part in satisfying the varied needs of the community. (1949)

However, rationalization and improvements within the industry clearly resulted from some of the transferred initiatives discussed above. In 1948, there were approximately 95,400 employees within the industry. By 1951 this had increased to 106,800. However, by the end of 1958, this had dropped to 98,000, and by 1970 it had dropped even further to 86,000 (Historical Record, 1970). A commentator, writing in 1972 considered that although the number of firms producing domestic furniture since 1952 had considerably decreased, productivity had increased markedly due to the use of new materials, improved management methods, special- purpose machines and 'in particular to simplified and rationalised design to reduce the number of components'. (Heughan, 1972)

The census figures demonstrate this.

\section{Insert Table D here}

These changes, must, in part at least, be attributed to the changes under discussion in this paper.

Although the British furniture trade, in varying degrees, generally acknowledged the benefits of technology transfer in a wide sense, they selectively engaged with it. The applications based partly on Government initiatives, and partly on the power of the adoption networks. However, the main incentive was the potential profitability that would accrue to those who embraced appropriate aspects of the new technologies. The widespread adoption of materials such as plywood and heat setting glues, which reduced the skills level needed and thus costs, and the implementation of materials handling systems and line production methods in many medium and larger scale businesses for example, again reduced costs and increased profitability.

Even if selected technologies can be successfully transferred relatively quickly, their cultural acceptance often takes much longer. The fears of the erosion of craft skills expressed early in the twentieth century were still cited in the 1980s as an issue in the adoption of new methods. The nostalgic words of a traditional furniture manufacturer, talking about his business in the late1980s, encapsulate the problem:

[Now] were actually making money not furniture... whereas then [1950-60s] we 
were making furniture and not money. (Attfield, 1990)

This sentiment might well be applied to many other technology transfer efforts of both the same and later time periods.

\section{References}

Aluminium Laboratories Ltd. (1946). 25th June. Privately published report, Banbury, unpaginated.

Anglo-American Council on Productivity, (1952). Furniture, Report of a Visit to the USA in 1951 of a productivity team representing the British furniture Industry, London: AACP.

Attfield, J. (1990). Then we were making furniture, not money: a case study of J. Clarke Wycombe furniture makers, Oral History, Autumn, 54-57.

Bland, S. (1995). Take a Seat. High Wycombe: Parker Knoll.

Braddell, D.A. (1942). Common sense in furniture design. Journal of the Royal Society of Arts, 90, $3^{\text {rd }}$ April, 312-3.

British Furniture Manufacturers Assoc. (1949) Private Papers 38/49, Report of Mr Kindel of US National Association of Furniture Manufacturers.

Board of Trade. (1946). Working Party Reports Furniture, London: HMSO.

British Productivity Council. (1954). A Review of Productivity in the Furniture Industry. London: BPC.

Collins, J.B. (1988). Design in Industry Exhibition, National Gallery of Canada, 1946, Material Culture Bulletin, 27, Spring..

Dreyfuss, Henry (1960). Product Studies: Aluminum. Industrial Design, 7 May 1960.

Edwards. C. (2001). Aluminium Furniture 1886-1986. Journal of Design History, 14:3, 203-226.

Geffrye Museum (1974), CC41Utility furniture and fashion Exhibition Catalogue. London.

Heal Plymet catalogue, (1947).

Historical Record of the Census of Production, (1970), London: HMSO.

Industrial Design, May 1960.

Jeremy, David (Ed.) (1992) The transfer of international technology: Europe Japan and the USA in the twentieth century. Aldershot: Edwards Elgar.

Kape, W.J. (1953), Cabinet Maker, 28 November.

Kirkham, P. (1995). Charles and Ray Eames. Designers of the twentieth century, Cambridge, Mass.: MIT Press.

Lebus, H. (1965). A History of Harris Lebus 1840-1947, unpublished typescript.

Light Metals, October 1946.

Logie, G. (1947). Furniture From Machines. London: Allen and Unwin.

Martin, J. E. (1966), Greater London, an industrial geography. London: Bell.

Modern Metals, June 1950.

Nelson, G. (1947), The Furniture Industry. Fortune, January 1947.

OEEC, (1953), Technical Assistance Mission no. 59A. Timber and Furniture Industry., 
Paris.

Prais, S.J. (1981). Productivity and Industrial Structure. Cambridge: Cambridge University Press.

Pritchard, J. (1984). A View from a Long Chair. London: Routledge.

Pye, D. (1968). The Nature and Art of Workmanship. Cambridge: Cambridge University Press.

Rogers, E.M. (1983/1995), Diffusion of Inventions, New York: Free Press.

Russell, G. (1968). Designer's Trade. London:

Sawyer, J. (1954). The Social Basis of the American System of Manufacturing, Journal of Economic History, 14, 361-79.

Standing Committee on the Investigation into Prices (Profiteering Acts 1919 and 1920), London: HMSO.

The Times.

Tomlinson, J. and Tiratsoo, N. (1998) Americanization beyond Mass production, in Kipping, and Bjarnar, (Eds). The Americanization of European Business. London: Routledge.

Tomlinson, J. (2002). The British Productivity Problem in the 1960s. Past and Present, $175,188-210$.

Trippe, P. (1962). Mass Production Techniques in a Craft Industry. Mass Production, 38, February.

White, N. (1973). Management of design services. London: Bell.

Zeitlin, J. (1995). Flexibility and Mass Production at War: Aircraft Manufacture in Britain, the United States, and Germany, 1939-1945, Technology and Culture, 36, Pt. 1.

Zeitlin, J. and Herrigel, G. (2000). Americanization and its limits. Oxford: Oxford University Press. 
Table A

(Working Part Report 1946: p.158 extrapolated)

USA UK \% Difference between US and UK outputs

Population
Workers in Furniture Industry
Gross output
Average net output per head Cabinet making
employing more than 500 workers
Average net output per head Cabinet making
employing from 100 to 300 workers
Average net output per head upholstery
employing more than 500 workers
Average net output per head upholstery
employing from 100 to 300 workers

$\begin{array}{cc}137,000,000 & 45,000,000 \\ 143,000 & 100,000 \\ £ 95 \mathrm{M} & £ 37 \mathrm{M} \\ £ 289 & £ 261\end{array}$

$£ 325$

$£ 220$

US $+10 \%$

$£ 325$

$£ 269$

US $+47 \%$

$£ 460$

$£ 211$

US $+71 \%$

$£ 335$

US $+58 \%$ 


\section{Table B}

Comparative Costs Scheme (Furniture Development Council)).

Value added Sales

Av. Labour Cost

Capital to turnover

Profit to real capital
1954

.967

2130

$18.6 \%$

$47.5 \%$

$9.5 \%$
1955

1061

2320

$17.8 \%$

$44 \%$

$9.8 \%$
1956

1250

2644

$16.3 \%$

$42.5 \%$

$12.6 \%$ 
Table C

Analysis by employment size of furniture and upholstery businesses in the UK

1948 -1954 (based on Historical Record of the Census of Production 1907-1970, 1972, HMSO)

Establishment Size (no. of employees) $\quad 1-24 \quad 25-99 \quad 100-\quad 500-$

1948

Net Output per employee $(£)$

Number of estab'mnts

Total employment

$\begin{array}{cccc}(£) 484 & (£) 539 & (£) 497 & (£) 494 \\ \text { n/a } & 618 & 184 & 11 \\ 22,500 & 29,500 & 34,000 & 9,300\end{array}$

1951

\begin{tabular}{|c|c|c|c|c|}
\hline Net Output per employee & (£)541 & (£)513 & $(£) 574$ & $(£) 763$ \\
\hline Number of estab’mnts & $\mathrm{n} / \mathrm{a}$ & 711 & 221 & 15 \\
\hline Total employment & 20,500 & 34,100 & 40,900 & 11,400 \\
\hline \multicolumn{5}{|l|}{1954} \\
\hline Net Output per employee & $(£) 710$ & (£)644 & $(£) 681$ & $(£) 990$ \\
\hline Number of estab'mnts & $\mathrm{n} / \mathrm{a}$ & 627 & 217 & 14 \\
\hline Total employment & 17,300 & 30,700 & 41,800 & 10,600 \\
\hline $\begin{array}{l}\text { \% increase in net output per employee } \\
\text { from } 1948 \text { to } 1954\end{array}$ & $46 \%$ & $19 \%$ & $37 \%$ & $100.4 \%$ \\
\hline $\begin{array}{l}\text { \% increase (decrease) in total employees } \\
\text { from } 1948 \text { to } 1954\end{array}$ & $(23 \%)$ & $4 \%$ & $23 \%$ & $14 \%$ \\
\hline
\end{tabular}




\section{Table D}

Analysis of output and establishment of furniture and upholstery businesses in the UK

1954 and 1970 (based on Historical Record of the Census of Production 1907-1970, 1972, HMSO)

\begin{tabular}{|c|c|c|c|c|}
\hline \multicolumn{5}{|l|}{$\begin{array}{l}\text { Establishm } \\
\mathbf{1 9 5 4}\end{array}$} \\
\hline Net Output per employee & $(£) 710$ & $(£) 644$ & (£)681 & (£)990 \\
\hline Number of estab'mnts & $\mathrm{n} / \mathrm{a}$ & 711 & 221 & 15 \\
\hline Total employment & 20,500 & 34,100 & 40,900 & 11,400 \\
\hline \multicolumn{5}{|l|}{970} \\
\hline Net Output per employee $(£)$ & $\begin{array}{l}(£) 1800 \\
\text { estimate }\end{array}$ & $(£) 3073$ & $(£) 1951$ & $(£) 258$ \\
\hline Number of estab'mnts & 1806 & 381 & 179 & 16 \\
\hline Total employment & 16,600 & 20,300 & 37,000 & 12,10 \\
\hline
\end{tabular}

